\title{
Nail Design by Appling the Figurative Characteristics of Minimalism and Maximism
}

\author{
Sue-kyung $\mathrm{Cho}^{1}$, Young-Sam $\mathrm{Kim}^{2 *}$ \\ ${ }^{1}$ Department of Cosmetics Engineering, Konkuk University, Seoul, Korea \\ ${ }^{2}$ Department of Image Industry, Graduate School of Engineering, Konkuk University, Seoul, Korea
}

"Corresponding author: Young-Sam Kim, Department of Image Industry, Graduate School of Engineering, Konkuk University, 120 Neungdong-ro, Gwangjin-gu, Seoul 05029, Korea

Tel.: +82 24500463

Email: gracehelen@konkuk.ac.kr

Received October 31, 2019

Revised March 05, 2020

Accepted March 12, 2020

Published March 30, 2020

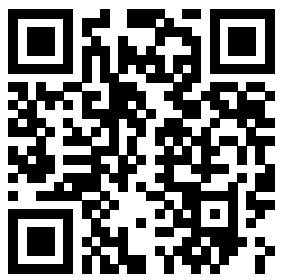

\begin{abstract}
Purpose: This study aims to present creative and original nail art design through ideas inspired by the formulation of minimalism and maximalism. Methods: For nail design production that utilizes minimalism and maximalism, we conducted both empirical and theoretical research through literature review and case studies. Moreover, through prior and empirical researches, photos were obtained for classifying and analyzing design cases that demonstrate how minimalism and maximalism are expressed. Result: Through analyzing design cases portraying the formulation of minimalism and maximalism, the works produced under the theme of a woman's life were selected and produced through the following stages: birth, growth, marriage, parenting, and twilight. Conclusion: This study confirms that nail design can be used as an important production material in the developmental and planning processes in various fields, because it is not limited to the nail art field but has become a trend in life. Furthermore, it can be used as a concept associated with various techniques and creative and original designs can be created through storytelling.
\end{abstract}

Keywords: Minimalism, Maximalism, Formability, Utilization, Nail design

\section{Introduction}

현재 여성의 전반적인 사회진출과 함께 이미지에 대한 관심이 높 아지고 있으며, 정치, 경제, 사회, 문화 등 어느 분야에도 빠질 수 없는 중요한 부분을 차지하고 있다. 또한 사회 전반의 융합 트랜드 와 양극화 현상은 이러한 뷰티 분야에서도 예외는 아니어서, 속은 복잡하지만 다채롭고 화려한 맥시멀리즘(maxmalism)과 겉은 단순 하고 세련된 미니멀리즘(minimalism)이 공존하고 있다.

손톱이라는 작은 공간에 네일 케어의 청결 목적을 넘어 호기심을 실현하는 도전적 아트나 화려한 면의 아트를 추구하면서 패션이나 헤어, 메이크업 등의 분야에서도 나타나듯이 때와 장소 상황에 맞 는 네일 아트를 선호하고 있다.

특히 제 2 의 두뇌라고 하는 손에서 손톱은 우리의 생활에 매우 중 요한 역할을 하며, 소통하는 언어로도 사용한다. 때문에 손톱이 없 다면 잡거나 쥐는 일 섬세한 작업도 할 수 없다. 또한 네일 아트는 손톱이나 발톱을 미적으로 표현하는 것으로, 단순히 네일 에나멜
등의 색조를 입혀 아름답게 보이게 하는 것뿐 만 아니라 그림을 그 린다든지 비즈나 보석을 붙이는 등으로 손톱이나 발톱에 예술적인 표정을 살리는 작업이라고 할 수 있다(Kim et al. 2012).

미니멀리즘이란 말이 생기기 전에 $\mathrm{ABC}$ 아트, 거부 미술, 즉물 미 술, 차가운 미술 등의 많은 이름이 쓰였다. 미니멀리즘이란 '최소한 의', '최소의' 라는 Minimal과 주의라는 ism이 결합한 단어로 1960 년대 뉴욕을 중심으로 출연한 미술사조(Hwang et al., 2018)이다.' 적은 것이 더 많다', '작은 것이 아름답다'는 심미적 원칙에 기초를 두고 있다.

1960 대 미국에서 유행한 미니멀리즘은 평면성과 구획이라는 가 장 기본적인 요소만을 남기고 불필요한 요소들을 없애 버렸고, 색 채와 형태를 단순화한 절제된 양식에 극도의 절제와 단순미를 부각 시켰다(Hwang et al., 2018). 이러한 현상은 이집트의 피라미드, 쉐이커 교도들의 가구와 동양의 노자사상, 일본의 전통 건축 및 젠 (Zen)양식의 배경사상과 일맥상통한다. 선행연구에서 미니멀리즘 특성을 단일성, 단순성, 환경성, 반복성, 환원성으로 분류하여 창 
의적인 헤어스타일을 제고하였고, 단순성, 순수성(Kwon \& Lee, 2019), 단일성, 환원성으로 분류하여 메이크업 특성을 연구하였고, 젠 스타일은 기본 장식을 배제한 단순성과 미니멀리즘의 형태로 발 전한 절제된 미를 연구하였다(Cho \& Kim, 2000). 이에 본 연구자 는 미니멀리즘 특성을 단순성, 단일성, 순수성, 반복성, 물질성으로 분류하였다.

맥시멀리즘이란 원색적인 화려한 색상, 과감하고 과장된 장식과 풍성한 부피감 등 과장된 형태의 문화 예술적 경향이다. 단순하고 간결한 장식을 최소화하고 세련되고 우아한 미술 또는 그러한 경향 을 의미하는 미니멀리즘과는 반대의 개념인 최대주의 극대주의 뜻 을 지니고 있다(Jeong \& Jung, 2009). 1960년대 팝, 1970년대 펑 크와 1990년대 대표적인 미니멀리즘에 염증을 느껴 디자이너들이 과장된 장식과 재미를 추구하는 맥시멀리즘의 디자인을 선보이게 된다((Kim \& Kim, 2011).

선행연구에서 맥시멀리즘 특성을 확대과장성, 장식성, 퓨전성, 실험성으로 분류하여 미래 니트 디자인의 새로운 관점과 기획 아 이디어를 제공하였고, 확대과장성, 장식성, 혼합성, 비구조성으로 분류, 패션의 표현 특성을 응용한 작품제작, 스타일링의 연출 요 소, 현대 맥시멀리즘과 패션 스타일링 이미지를 제시하였다(Park, 2012). 이에 본 연구자는 맥시멀리즘 특성을 확대과장성(Lee \& Roh, 2012), 장식성, 실험성, 혼합성, 비장식성으로 분류하였다.

이에 본 연구에서는 간결하고 단순하지만 불필요함을 지양하고, 사물의 본질을 추구하는(Choi \& Kim, 2012) 미니멀리즘의 조형성 과 복잡하지만 화려한 맥시멀리즘의 조형성을 활용한 디자인 사례 를 네일 아트에 적용하고자 한다. 네일 아트에 있어서 미니멀리즘 과 맥시멀리즘의 조형성을 활용한 창의적인 디자인은 개개인의 개 성 표현뿐만 아니라 자신의 이미지 개선에도 도움이 될 것으로 생 각되는 바, 미니멀리즘과 맥시멀리즘의 조형성을 활용한 네일 아트 아이디어를 통해 창의적이고 독창적인 네일 아트 디자인을 제시하 는데 본 연구에 목적이 있다. 본 연구는 미니멀리즘과 맥시멀리즘 의 문헌고찰을 통하여 이를 응용한 디자인 사례를 분류하여 본 네 일 디자인에 표현할 보다 객관적 자료를 분석하고자 한다. 또한 많 은 네일 아트 중 미니멀리즘과 맥시멀리즘의 조형성을 활용하여 주 제를 여성의 일생으로 선정하고, 탄생, 성장, 결혼, 육아, 황혼의 일 생을 통한 미묘한 감정을 네일 디자인으로 승화해 표현하여 아름다 움을 표현하는 데 국한하지 않고 현대인의 라이프 스타일과 이미지 를 상황에 따라 변화시키는 등 각자의 개성적인 표현에 도움이 되 여, 나아가 문화 사조의 조형성 활용이 네일 아트산업에도 기초 자 료가 되고자 한다.

\section{Methods}

\section{1. 연구문제}

본 연구는 미니멀리즘과 맥시멀리즘의 조형성을 활용한 네일아 트 아이디어를 통해 창의적이고 독창적인 네일 디자인을 제시하는 데 본 연구에 목적이 있다. 다양하고 많은 네일아트 중 미니멀리즘 과 맥시멀리즘의 조형성을 활용한 작품제작은 탄생, 성장, 결혼, 육 아, 황혼의 일생을 통한 미묘한 감정을 네일 아트로 승화하기 위해 여성의 일생이라는 주제를 선정하였다. 이에 연구 문제는 다음과 같다.

첫째, 미니멀리즘과 맥시멀리즘의 조형성을 보여주는 디자인 사 례에 대해 알아본다.

둘째, 미니멀리즘과 맥시멀리즘의 조형성을 활용한 네일아트를 여성의 일생이란 주제로 작품을 제작한다.

\section{2. 자료수집 및 분석방법}

본 연구는 국내 단행본, 네일아트 서적, 패션서적, 학술논문 등 네일아트에 관련한 문헌 고찰을 진행하였다. 그리고 실증적 연구 를 위하여 국내외 네일 전문잡지와 인터넷 웹사이트, SNS, 인스타 그램, 페이스북에서 자료를 수집하였다. 미니멀리즘과 맥시멀리즘 의 조형성은 선행 연구를 조사하여 고찰하고 네일아트 특성을 고려 한 조형성을 도출한다. 또한 미니멀리즘과 맥시멀리즘의 조형성이 공존하는 네일아트를 도출하여 각각의 조형적 공존 유형 특성을 분 석하고 네일아트 특성을 도출하였다. 본 연구는 네일 서비스와 네 일 교육산업에 종사하는 7명의 전문가에게 자문을 의뢰하여 모티 브 사진을 유형별로 3 개씩 선정해서 디자인을 기획하였다.

\section{Results}

\section{1. 디자인 사례}

미니멀리즘과 맥시멀리즘의 조형성을 보여주는 디자인 사례로는 건축, 인테리어, 미술, 음악, 산업디자인, 토탈코디네이션으로 분류 하였다.

미니멀리즘의 조형성을 통한 네일아트를 보면 단순성의 무장식, 무색상은 극도로 절제된 색채와 장식이 없는 소박하고 간결한 표현 이며, 매트하고 단순한 것 또한 미니멀리즘의 대표적인 특징적 표 현이라고 할 수 있다. 맥시멀리즘 네일은 과도한 장식을 추가하며 기분전환을 해주는 역할을 한다. 맥시멀리즘의 융합화, 극대화, 통 합화, 순환과 반복을 바탕으로 확장해 간다면 네일아트의 창의적인 디자인은 무한하다.

\section{2. 네일아트를 여성의 일생이란 주제로 제작한 작품들}

본 연구에서는 단순하고 간결한 미니멀리즘과 화려하고 과장된 맥시멀리즘이 가지고 있는 특성을 네일 아트로 표현하고자 한다.

미니멀리즘의 조형성인 단순성, 단일성, 순수성, 반복성, 물질성 과 맥시멀리즘의 조형성인 확대 과장성, 장식성, 혼합성, 실험성, 

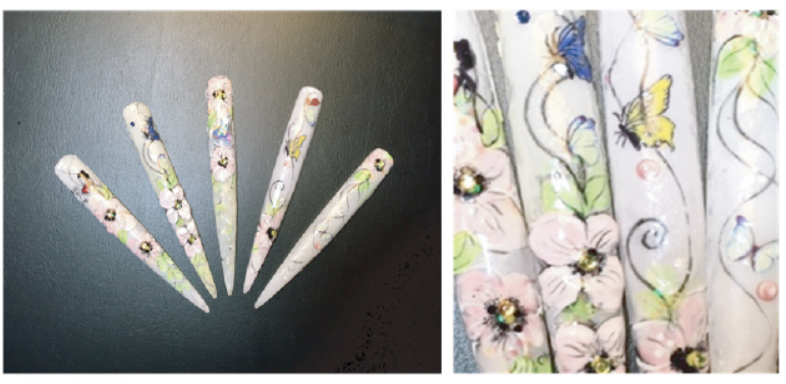

Figure 1. The birth of works I.

In the design composition, five oblong tips were used to signify birth. The colors in the work image were based on emerald pearl and persimmons, and the flques colors red/soft, yellow/light, green yellow/light, purple blue, red/vivid, white and black create a mysterious atmosphere surrounding the birth.
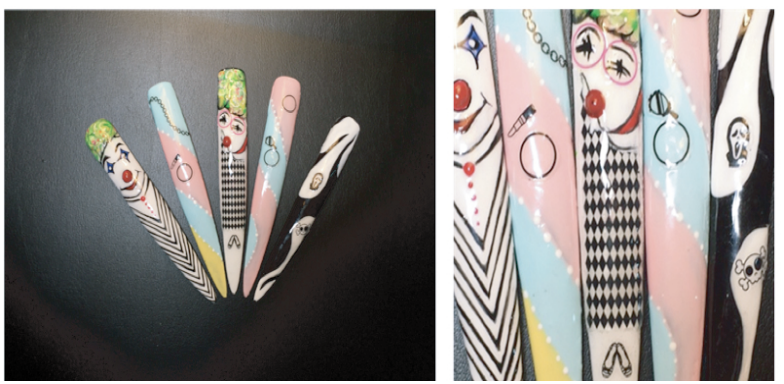

Figure 2. Works II growth.

Here, the design composition of growth is conceived, contemplating the repeatability of minimalism and the enlargement of maximalism. The colors blue green/light, purple blue, red/vivid, black, red/soft, yellow/light, green yellow/light, and green/vivid are used to express the different emotions of puberty.

비구조성을 활용하여 '여성의 일생'이라는 주제를 선정하였다. 미니 멀리즘과 맥시멀리즘의 조형성을 유형별로 선정하여 이미지 사진 3 장을 선정하였다. 탄생, 성장, 결혼, 육아, 황혼이라는 다섯 단계 의 스토리를 가지고 우리가 살아가면서 한번쯤은 생각해 봐야할 인 생의 일대기이기에 네일 아트 작품으로 인생을 돌아보는 기회가 되 었으면 하는 바램으로 5 개의 작품을 제작하였다.

Figure 1 작품 I 은 생명의 탄생이다. 남녀 간의 사랑, 꽃과 나비 의 조화는 봄을 연상하면서 만물의 탄생을 알리고 새싹이 솟아오르 는 생동감으로 탄생의 경이로움을 표현하였다. 미니멀리즘의 단순 성과 맥시멀리즘의 비구조성의 조화는 단순하면서 꽃 위의 하트 팟 츠는 어울리지 않는 비구조적인 것을 연상하면서 작품을 제작하였 다.

Figure 2 작품 II 는 성장이다. 보통 사춘기 아이들은 자신이 어 른이라고 생각하며 어른처럼 행동하지만 여전히 어린티를 못 벗어
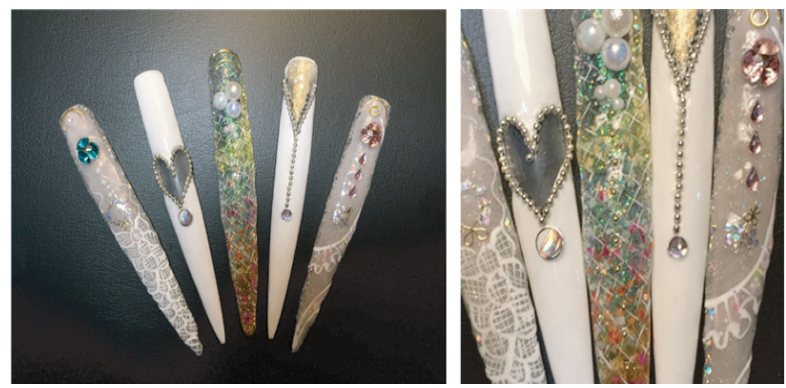

Figure 3. Works III marriage.

This work features five oblong tips that express marriage and uses such colors based on white, lace, and pulp to express a beautiful wedding ceremony. The colors used were yellow red/white, white, red/white, green yellow, red purple/light, and red purple/white to project the excitement of marriage.
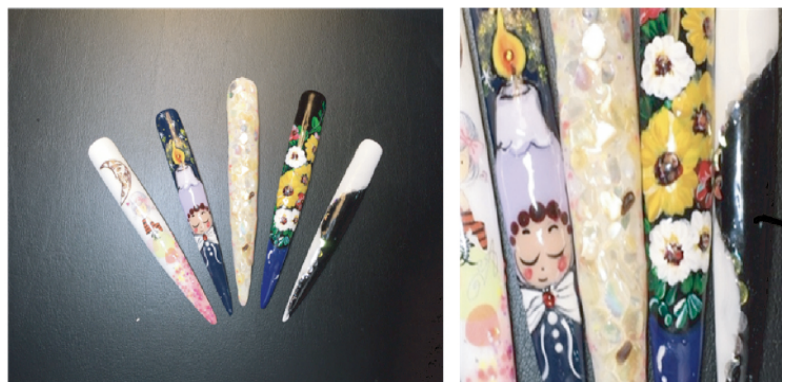

Figure 4. Works IV parenting.

Five oblong tips were used here to depict the child, and the image used a contrast of black and white to represent the poles of life and the images of mystery in prayer. The colors purple/soft, yellow red/vivid, white, black, green/deep, yellow red/light, red/ vivid, green/white, blue green/whites were used to express the desperation of the child.

나는 어린아이로 보이는 것을 표현하였다. 특히 남의 시선을 의식 하는 화장을 통해 자신을 드러내는 행동을 한다. 그 중 삐에로가 가 장 상징적으로 떠 오른다. 조르주 앙리 루오의 작품인 뻬에로는 우 스꽝스러운 즐거움의 대상이지만, 루오는 가장 인간적인 면을 가진 대상이라고 생각했다. 삐에로는 자유롭고 욕심 없고 괴로움을 참고 살아가는 청소년기를 잘 표현해주고 있다.

Figure 3 작품 III은 결혼이다. 사랑하는 사람과 결혼을 하는 행 복한 모습을 담았다. 결혼하면 신부의 깨끗하고 순수한 이미지가 떠오른다. 레이스로 바탕을 깔아 질감을 표현하여 풍성함을 주었 다. 미니멀리즘의 순수성과 맥시멀리즘의 장식성의 조화는 순수함 에 장식적인 것을 더해 결혼식의 화려함을 표현하였다.

Figure 4 작품 $\mathbb{V}$ 는 육아이다. 하나의 생명이 인격체가 되고 독 립할 때까지 지켜봐야 하는 인고의 시간과 아이를 기르는 감정을 표현하였다. 미니멀리즘의 단일성과 맥시멀리즘의 실험성의 조화 

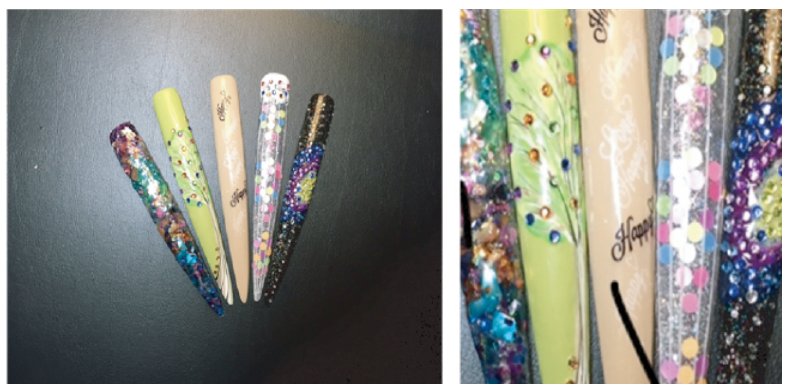

Figure 5. The $\mathbf{V}$ twilight.

Looking back on my life, I have expressed my work by imagining myself smiling. My years were not spent in vain but rather in moments of blinding beauty.l used five oblong tips to express twilight, with the colors intending to make it a happy twilight: green yellow/light, blue/light, purple/soft, yellow red/light, red purple/ deep, purple blue/deep, black, blue green/vivid, and yellow red/ white.

를 연상하면서 작품을 제작하였다. 자갈밭 길을 걷는 심정으로 아 이를 키우면서 항상 해만 바라보는 해바라기처럼 아이만 바라보는 엄마의 마음이 담겨 있다. 인생에서 가장 힘들지만 보람이 있는 시 기라고 할 수 있다.

Figure 5 작품 V는 황혼이다. 자신의 인생을 돌아보며 미소를 지을 수 있는 나의 모습을 상상하며 작품을 표현하였다. 그 동안 살 아온 세월이 헛되지 않고 순간순간 눈이 부시게 아름다운 느낌을 표현하였다. 조성일 화가의 '인간의 뇌'를 승화시킨 그림에서 영감 을 받아 황혼을 표현해 보았다. 기본에 충실한 삶을 표현하기 위해 베이지 색을 썼으며, 자개로 찬란했던 젊을 시절의 아름다움을 표 현하였다. 미니멀리즘의 물질성과 맥시멀리즘의 혼합성의 조화는 본질적인 것으로 돌아가려는 특성과 과거, 현재, 미래를 연상하면 서 작품을 제작하였다.

\section{Discussion}

지금까지 미니멀리즘과 맥시멀리즘 사조에 대한 연구는 현대 건 축에서의 미니멀리즘의 의미와 특성에 관한 연구(Lee, 1997), 맥 시멀리즘 특징을 이용한 메이크업 연구(Kim \& Kim, 2011), 2000 년대 패션에 표현된 미니멀리즘과 맥시멀리즘의 비교 미학적 연구 (Park, 2012), 맥시멀리즘의 조형적 특성을 활용한 패션 디자인 연 구(Lee \& Yum, 2017), 그리고 미니멀리즘의 조형의 동양 선 사상 적 해석 등이다(Hwang et al., 2018). 이러한 연구들은 미니멀리 즘이나 맥시멀리즘의 한 가지 사조에 국한 되거나 실내디자인, 헤 어, 메이크업 중심으로 연구 되어있고 미술, 음악, 건축, 뷰티 등의 예술 분야는 다양하게 연구 되었으나 네일 아트와 관련된 미니멀리
즘과 맥시멀리즘의 조형성을 활용한 연구는 아직 미비한 실정이다. 따라서 미니멀리즘과 맥시멀리즘의 조형성을 보여주는 디자인 사 례를 분석하여 창의적이고 개성 있는 '여성의 일생'이란 네일 디자 인을 제시하였다.

\section{Conclusion}

본 연구는 문헌 고찰을 통해 미니멀리즘과 맥시멀리즘의 조형성 을 분석하고, 나아가 이를 활용하여 창의적이고 개성 있는 자기표 현을 할 수 있는 네일 디자인을 제시하였다.

미니멀리즘과 맥시멀리즘의 개념 및 발생 배경, 조형적 특성을 분석하였고, 융합의 개념, 배경을 알아 본 후 네일아트의 개념과 역 사, 네일 서비스 분류 등을 고찰하였다. 또한 미니멀리즘과 맥시멀 리즘의 조형성을 보여주는 디자인 사례를 분석하여 네일아트 작품 을 제작하였고, 각 작품의 제작 의도와 표현방법에 대해 서술하였 다.

연구의 결과를 요약하면 다음과 같다.

첫째, 미니멀리즘의 조형성은 단순성, 단일성, 순수성, 반복성, 물질성이며 맥시멀리즘의 조형성은 확대과장성, 장식성, 혼합성, 실험성, 비구조성이다.

둘째, 융합은 두 가지 이상을 합한 현상으로 전 세계적으로 기술, 과학, 인문 각각의 세분화된 학문들을 통합하고 결합할 뿐만 아니라 더 나아가 응용함으로써 새로운 분야를 창출해 가는 과정이다.

셋째, 네일아트는 손톱과 발톱을 미적으로 표현한 것이며 5000 년 전 고대 이집트과 중국에서 신분을 나타내는 것으로 사용되었고 네일 디자인 중 평면 네일아트 기법으로는 핸드페인팅, 마블, 포크 아트, 워터데칼, 스트라이핑 테이프, 에어브러쉬와 융합 네일아트 기법으로는 라인스톤, $2 \mathrm{D}$ 아트, $3 \mathrm{D}$ 아트, 믹스미디어 등이 있다.

넷째, 미니멀리즘과 맥시멀리즘의 조형성을 보여주는 디자인 사 례는 건축, 인테리어와 미술, 음악, 산업디자인, 토털코디네이션 전 반에 나타나 있으며, 미니멀리즘과 맥시멀리즘의 조형성을 활용한 네일 디자인을 여성의 일생이란 주제로 제작한 작품은 다음과 같다.

작품 I 탄생은 미니멀리즘의 특성인 단순성과 맥시멀리즘의 특 성인 비구조성을 분석하여 제작한 작품으로 단순한 바탕에 탄생과 연상되는 꽃과 나비, 사랑을 단순하면서 비구조적으로 표현하였다.

작품 II 성장은 미니멀리즘의 특성인 반복성과 맥시멀리즘의 특 성인 확대과장성을 분석하여 제작한 작품으로 반복되는 패턴은 성 장기의 일상의 반복을 나타냈고, 상반되는 색상의 반복은 인간의 양면성을, 삐에로처럼 남의 눈을 의식하는 성장기에 외모에 관심을 많이 가지는 모습을 연상하면서 표현하였다.

작품 III 결혼은 미니멀리즘의 특성인 순수성과 맥시멀리즘의 특 성인 장식성을 분석하여 제작한 작품으로 결혼의 이미지인 순수함 과 화려함을 접목시켜 인생의 가장 아름다운 결혼식 장면을 연상하 
면서 표현하였다.

작품 $\mathrm{V}$ 육아는 미니멀리즘의 특성인 단일성과 맥시멀리즘의 특 성인 실험성을 분석하여 제작한 작품으로 아이를 키우는 과정이 힘 들기도 하지만 세상에서 가장 큰 보람을 느끼는 시기이므로 아이바 라기와 항상 기도하는 모습을 연상하면서 표현하였다.

작품 $\mathrm{V}$ 황혼은 미니멀리즘의 특성인 물질성과 맥시멀리즘의 특 성인 혼합성을 분석하여 제작한 작품으로 각자의 인생은 때론 불행 했고 때론 행복했지만 그럼에도 살아서 좋았다는 것을 느끼며 어느 하루 눈부시지 않은 날이 없었기에 살아갈 가치가 있는 아름다운 삶을 연상하면서 표현하였다.

이와 같이 본 연구는 미니멀리즘과 맥시멀리즘 조형의 특징을 활 용한 네일 디자인을 제작하였다. 또한 네일 디자인에 다양한 기법 으로 연상되는 이미지를 표현하고, 스토리를 부여함으로써 창의적 이고 독창적인 디자인 창출에 무한한 가능성을 부여할 수 있음을 확인하였다.

본 연구를 통해 제작된 네일 디자인이 현대인의 다양한 니즈와 욕구를 충족시키는데 도움이 되기를 바라며, 사조의 융합이 네일아 트 분야에 국한 되지 않고 생활전반의 트렌드로 자리 잡은 만큼 다 양한 분야에서 이를 발전시키고 기획하는데 중요한 자료로 활용될 수 있기를 기대한다.

This work is part of the Sue-kyung Cho's M.Sc.thesis at the Konkuk University, Seoul, Korea.

\section{Author's contribution}

Through a literature review, SKC analyzed the formation of minimalism and maximalism and used them to present a creative and unique nail design. YSK has contributed greatly to the review and writing of the manuscript. All authors read and approved the final manuscript.

\section{Author details}

Sue-kyung Cho (Graduate student), Department of Cosmetic Engineering, Konkuk University,120 Neungdongro, Gwangjin-gu, Seoul 05029, Korea; Young-Sam Kim (Professor), Department of Image Industry, Graduate School of Engineering, Konkuk University, 120 Neungdong-ro, Gwangjin-gu, Seoul 05029, Korea.

\section{References}

Choi EK, Kim JS. The trend of manish hair style in aspect of features of minimalism. Asian Journal of Beauty and Cosmetology, 10: 267-271, 2012.

Cho JM, Kim YH. A study on the ZEN(禪) style in contemporary fashion. Journal of the Korean Society of Costume, 50: 163-175, 2000.

Hwang YJ, Chang DR, Kim DB. A study of thought of Seon on minimalism. Journal of Basic Design and Art, 19: 593608, 2018.

Jeong $\mathrm{SH}$, Jung $\mathrm{HJ}$. Characteristic to express maximalism fashion appearing in fashion collection. Journal of the Korean Fashion \& Costume Design Association, 11: 155-167, 2009.

Kim HJ, Kim HK. A study on make-up designs based on maximalist characteristics: focusing on overseas collection from the 2005 S/S to 2011 F/W seasons. Journal of Fashion Design, 11: 99-115, 2011.

Kim SY, Paik SY, Kang SM. The nail design technique applying with UV gel. Asian Journal of Beauty and Cosmetology, 10: 179-184, 2012

Kwon OG, Lee JG. A purity study of minimalism: focusing on the purity of Dan Flavin's works. Journal of the Korea Intitute of Spatial Design, 55: 33-44, 2019.

Lee JH, Noh YS. A study on the formative character of maximalism shown in the works of Alexander McQueen. Journal of the Korean Society of Costume, 62: 165-168, 2012.

Lee JW. A study on meaning and characteristics of minimalism in contemporary architecture. Korean Institute of Interior Design Journal, 13: 150-160, 1997.

Lee SD, Yum MS. Study on the fashion design using the formative characteristics of maximalism. Fashion \& Textile Research Journal, 19: 681-691, 2017.

Park EK. A comparative study on minimalism and maximalism in the 2000s fashion. Journal of the Korean Society of Costume, 62: 100-117, 2012. 


\section{국문초록}

\section{미니멀리즘과 맥시멀리즘의 조형성을 활용한 네일 디자인 연구}

조수경 ${ }^{1}$, 김영삼 ${ }^{2 *}$

${ }^{1}$ 건국대학교 화장품 공학과, 서울, 한국

${ }^{2}$ 건국대학교 산업대학원 이미지산업학과, 서울, 한국

목적: 본 연구는 미니멀리즘과 맥시멀리즘의 조형성을 활용한 네일아트 아이디어를 통해 창의적이고 독창적인 네일아트 디자인을 제시하고자 한다. 방법: 미니멀리즘과 맥시멀리즘의 조형성을 활용한 네일 디자인 제작을 제작하기 위하여 문헌적 고찰과 사례연 구를 통한 이론적 연구와 더불어 실증적 연구를 하였다. 또한 선행연구와 실증연구를 통해 확보한 사진들을 통해 미니멀리즘과 맥 시멀리즘의 조형성을 보여주는 디자인 사례를 분류하고 사진자료를 분석하였다. 결과: 미니멀리즘과 맥시멀리즘의 조형성을 보여 주는 디자인 사례를 분석하여 여성의 일생이란 주제로 제작한 작품은 탄생, 성장, 결혼, 육아, 황혼으로 선정하여 제작하였다. 결론: 본 연구는 네일 디자인이 현대인의 다양한 니즈와 욕구를 충족시키는데 도움이 되기를 바라며, 조형성의 활용이 네일아트 분야에 국한 되지 않고 생활 전반의 트렌드로 자리 잡은 만큼 다양한 분야에서 이를 발전시키고 기획하는데 중요한 자료로 활용될 수 있기 를 기대하며 네일 디자인에 다양한 기법으로 연상되는 이미지를 표현하고, 스토리를 부여함으로써 창의적이고 독창적인 디자인 창 출에 무한한 가능성을 부여할 수 있음을 확인하였다.

핵심어: 미니멀리즘, 맥시멀리즘, 조형성, 활용, 네일 디자인

\section{참고문헌}

김수연, 백선영, 강상모. UV Gel을 이용한 네일 디자인 기법. 아시안뷰티화장품학술지, 10: 179-184, 2012.

김현진, 김혜경. 맥시멀리즘 특징을 이용한 메이크업 연구: $2005 \mathrm{~S} / \mathrm{S} ~ 2011 \mathrm{~F} / \mathrm{W}$ 국외 컬렉션을 중심으로. 한국패션디자 인학회지, 11: 99-115, 2011.

권오길, 이재규. 미니멀리즘 순수성 연구: 댄 플래빈 작품의 순수성 중심으로. 한국공간디자인학회논문집, $55: 33-44$, 2019.

박은경. 2000년대 패션에 표현된 미니멀리즘과 맥시멀리즘의 비교미학적 연구. 복식, 62: 100-117, 2012.

이서도, 염미선. 맥시멀리즘의 조형적 특성을 활용한 패션디자인 연구. 한국의류산업학회지, 19: 681-691, 2017. 이정욱. 현대건축에서의 미니멀리즘의 의미와 특성에 관한 연구. 한국실내디자인학회논문집, 13: 150-160, 1997.

이지현, 노윤선. 알렉산더 맥퀸(Alexander McQueen) 작품에 나타난 맥시멀리즘(Maximalism). 복식, 62: 165-168, 2012.

정선화, 정현주. 패션컬렉션에 나타난 맥시멀리즘 패션 표현유형 분석. 한국의상디자인학회지, 11: 155-167, 2009. 조정미, 김예형. 현대 패션에 나타난 젠(Zen: 선(禪)) 양식에 관한 연구. 복식, 50: 163-175, 2000.

최은경, 김주섭. 미니멀리즘의 특징에 따른 매니쉬 헤어스타일의 경향. 아시안뷰티화장품학술지, 10: 267-271, 2012. 황윤정, 장동련, 김동빈. 미니멀리즘의 조형의 동양 선(禪)사상적 해석. 기초조형학연구, 19: 593-608, 2018. 


\section{中文摘要}

\section{运用极简主义和极大主义的形象特征进行指甲设计}

趙秀景 ${ }^{1}$, 金永三 $^{2 *}$

建国大学化妆品工学科, 首尔, 韩国

2建国大学产业大学院影像产业学科, 首尔, 韩国

目的: 本研究旨在透过极简主义与极大主义的构想, 呈现创意与原创的美甲艺术设计。方法: 对极简主义和极大 主义的指甲设计作品, 通过文献回顾和案例分析, 进行实证和理论研究。此外, 通过前期和实证研究, 获得了 展示极简主义和最大主义如何表达的设计案例分类和分析的照片。结果: 通过对极简主义和极大主义的设计案例 的分析，选择了以女性生命为主题的作品，并将其分为出生、成长、婚姻、养育和黄昏等几个阶段进行创作。 结论: 指甲设计不仅局限于指甲艺术领域, 而且已经成为一种生活趋势, 可以作为各个领域发展和规划过程中的 重要生产材料。此外, 通过表达使人联想到指甲设计中各种技术的图像并赋予故事, 可以在创意和原始设计创 作中创造无限的可能性。

关键词: 极简主义，极大主义，造型性，活用，指甲设计 
